is slow so that six to eight hours after a six-hour dialysis the effective lowering of the serum lithium is only $60-70 \%$ of that indicated by the postdialysis sample. This rebound can be prevented by longer duration haemodialysis (12-16 hours) (fig. 3) and possibly a further dialysis some hours later if the initial predialysis lithium levels are extremely high or further lithium is likely to be absorbed from slow-release lithium capsules in the alimentary tract. Where symptoms are less severe and facilities

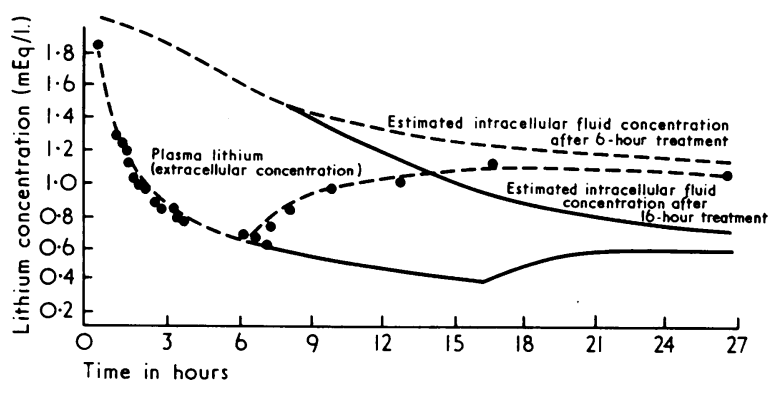

FIG. 3-Lithium removal by haemodialysis. Three pool model predictions when using data from case 2 . not available for haemodialysis peritoneal dialysis is effective in lowering lithium levels.

\section{References}

Amdisen, A , and Skjoldborg, H. (1969). Lancet, 2, 13.

Baastrup, P. C., and Schou, M. (1967). Archives of General Psychiatry, 16, 162.

Baastrup, P. C., Poulsen, J. C., Schou, M., Thomson, K., and Amdisen, A. (1970). Lancet, 2, 326.

Coppen, A., et al. (1971). Lancet, 2, 275.

Fieve, R. R., Platman, S. R., and Dlutchich, R. R. (1968). American fournal of Psychiatry, 125, 478. on Hartitzsch,

In press.
McCance, R. A. (1962). Age and Renal Function. Renal Disease. ed. D. A. K. Black, p. 157. Oxford, Blackwell Scientific.

Pye Unicam Ltd. (1969). Lithium in Blood Serum, Cambridge, Pye Unicam Ltd.

Robinson, R. A., and Stokes, R. H. (1959). Electrolyte Solutions, p. 246. London, Butterworths.

Schou, M., and Baastrup, P. (1967). Journal of the American Medical Association, 201, 696 .

Schou, M., Amdisen, A., and Trap-Jensen, J. (1968). American fournal of Psychiatry, 125, 520.

Wharton, R. N., and Fieve, R. R. (1966). American fournal of Psychiatry, 123, 706 Zall, H., Per-Olaf, G., and Myers, J. M. (1968). American fournal of Psy-
chiatry, 125, 549.

\title{
Dyslexia as Cause of Psychiatric Disorder in Adults
}

\author{
W. A. SAUNDERS, M. G. BARKER
}

British Medical fournal, 1972, 4, 759-761

\section{Summary}

A few patients may be of normal intelligence but have diffculties in reading, writing, and spelling, which are the main precipitants of a psychiatric disorder. In seven patients this illiteracy emerged only after intensive examination, as they had hidden it from employers, friends, and children. Characteristically these patients are often very sensitive about this disability and marital friction is common. They are also often noticeably resistant to remedial help.

\section{Introduction}

The World Federation of Neurology (1968) defined dyslexia as a disorder in children who, despite conventional classroom experience, fail to attain the language skills of reading, writing, and spelling commensurate with their intelleciual abilities. Ingram (1964) and others emphasized the accompanying difficulties in writing spontaneously and spelling correctly. Various authors have described associated psychiatric disorders in childhood and adolescence, and these have been summarized by Critchley (1970) as non-specific and pleomorphic neurotic patterns.

This report deals with psychiatric disturbances in adults of normal intelligence who have hitherto unrecognized difficulties in reading, writing, and spelling, which appear causally related to their psychiatric disturbance and subsequent referral to a psychiatrist. A recognizable neurotic pattern is evident in these patients.

Barrow Hospital, Bristol

W. A. SAUNDERS, M.B., M.R.C.PSYCH., Registrar (Present appointment: Senior Registrar, Bristol Royal Hospital for Sick Children)

M. G. BARKER, F.R.C.P., M.R.C.PSYCH., Consultant Psychiatrist

\section{Methods}

All patients in this study were assessed by using the Weschler Adult Intelligence Scale (W.A.I.S.). Those subtests which are thought to depend heavily on educational attainments are separately scored (verbal score), and the other subtests which are thought to reflect the innate intellectual ability of the subject are grouped together under a different category (Performance Score). The combined results are given as Full Scale. Ravens' Matrices is a further test which gives an estimate of intelligence independent of verbal skills and educational background. The other attainment tests used were the Schonell Graded Word Reading Test (Reading Test), and the Schonell Graded Word Spelling Test A (Spelling Test). The remedial course referred to below was the Audio-visual Programmed Reading Material (Brown and Bookbinder, 1966).

\section{Case 1}

A 39-year-old married screensman was referred by his general practitioner with a six-month history of depression, agitation, and subsequent exacerbation of his asthma. He was found to have been depressed since promotion at work. At the end of a lengthy examination he disclosed that he was unable to read or write, a fact he had concealed from his employers over the years. After his promotion to foreman he had had to rely on his workmates to perform the paperwork now expected from him. He had become moody and irritable at work, argued with the foreman on the opposite shift, and was reprimanded by his employers because of these rows.

$\mathrm{He}$ had a stormy marital relationship and was described by his wife as moody, violent, and always ill at ease socially. She also reported that he was suspicious of her, and without any grounds suspected that she was interested in other men. Since his elder child started school and had been learning to read and write, his relations with his children had become strained. This became much worse when his seven-year-old child was awarded a gold star for reading at school. 
Psychological Testing.-I.Q. W.A.I.S. verbal 90, performance 109. Full scale 99 (Ravens' matrices, score equivalent to I.Q. 112). Attainments.-reading age 8.6 years, spelling age 6 years.

Progress.-His depression improved with psychotherapy and tricyclic antidepressants. He started at a remedial reading clinic, but he soon stopped and refused further help.

\section{Case 2}

A 30-year-old housewife was referred to the psychiatric outpatient department together with her 31-year-old husband after a sudden aggressive and explosive outburst by her towards her husband. At the end of the interview she somewhat reluctantly gave the information that her husband could neither read nor write, and relied on her to do this for him. He had been forced to go to a dinner where he was unable to read the menu, and subsequently directed his resentment at her by making references to her weight. This upset her and caused the outburst for which she was referred. She described him as a moody, self-conscious individual who felt inferior to other men.

He was, however, a highly successful tradesman and had won several major awards, which necessitated social engagements where he was constantly on his guard against situations where his reading difficulties might become apparent; though surprisingly he had become secretary of a trade association-dictating the minutes to his wife when he returned home.

Psychological Testing.-I.Q. W.A.I.S. verbal 96, performance 94. Full scale 95. Attainments.-reading age 6.7 years, spelling age 5.6 years.

Progress.-The wife improved markedly when her husband was seen on a regular outpatient basis. He asked for help for his dyslexia, and arrangements were made for him to have individual lessons in reading. He agreed to this but only on condition they could be given privately. He is now able to read with some degree of fluency and the marital situation has improved correspondingly.

\section{Case 3}

A 31-year-old labourer was admitted to hospital under section 25 of the Mental Health Act. He had become violent after drinking beer while taking phenobarbitone tablets, prescribed by his general practitioner for occipital headaches. He later admitted he had had difficulties at work after promotion and was unable to cope with the responsibility. He had eventually asked for demotion to a light, unskilled job, having kept from his employers the fact that he was unable to read and write.

His wife reported that he was "broody" and very sensitive, and she gave the information that he was unable to read-but as he was so sensitive she asked that this be kept confidential. The patient later (after some prompting) "volunteered" this infomation himself but refused full psychological and attainment testing.

Abbreviated Psychological Testing.-I.Q. W.A.I.S. 100. Unable to read three-letter words.

Progress.-Settled quickly, but refused help with reading.

\section{Case 4}

A 29-year-old driver was seen as an outpatient when his marriage was in danger of breaking up. He had been intermittently depressed for several months, mainly in relation to his feelings of inadequacy and work difficulties. He had had several previous jobs, including that of warehouseman, which had ended in his dismissal because his writing was not good enough. As a driver he would hand the paper with his destination written on it to passers-by asking for directions, and so learnt from them what was written on the paper. He was finally admitted to hospital as he made little progress as an outpatient. It was then discovered that he had first become upset when his daughter, who had started school, began asking him to help her with her school work. He had taught himself to read and write after leaving school, but was still very sensitive about this, and a hesitant reader.

He was described by his wife as moody, violent, and jealous, and their marriage had been a stormy one. He had had several jobs and lost them after arguments with his superiors.
Psychological Testing.-I.Q. W.A.I.S. verbal 84, performance 67. Full scale 75 (underestimated because of difficulties in cooperation). Attainments.-reading age 12.2 years, spelling age 7.2 years.

Progress.-His depression responded to psychotherapy and tricyclic antidepressants. The marital relationship improved, but he refused help with reading.

\section{Case 5}

A 35-year-old coach builder was referred by his general practitioner with a three-month history of depression. He had become increasingly irritable and preoccupied with the thought that he had to "keep looking up to other people." He also had a fear that his children might ask him questions that he would be unable to answer. He had managed to become a skilled coach builder though unable to read or write. He was very sensitive about this and had kept it secret. Recently his work had necessitated his having to fill in schedules. He had memorized these and his wife had completed them at home.

His marriage was described as happy. He was sterile after mumps orchitis, and was having sexual intercourse with his wife up to five times nightly to prove his manliness. He said he still felt very upset when he saw his wife handling other people's babies. He had adopted two children now aged 7 and 4 years, and the elder child in particular was intelligent and continually asking for help with his reading. His wife had recently taken a part-time job in the evenings, and this meant he bore the brunt of his son's constant demands for help with school work. He had become profoundly depressed as a result of all this.

Psychological Testing.-I.Q. W.A.I.S. verbal 101, performance 96. Full scale 98. Attainments-reading age 7 years

Progress-He accepted the offer of remedial help initially but discharged himself against medical advice saying that he no longer wanted this help. He was readmitted shortly after this, and after further treatment for his depression was discharged. He was receiving individual reading help at the time of writing.

\section{Case 6}

A 62-year-old corporation parks worker was admitted to hospital agitated and depressed after an incident at work when the foreman joked about the "Humpty-Doodle" school, inadvertently making fun of a special school the patient had attended as a child owing to his poor attainments. After this he ruminated about his own illiteracy and how ashamed he felt about it, and became clinically depressed. He had always felt insecure and inadequate, but before this had been able to keep his feelings under control. He was happily married.

Psychological Testing.-I.Q. W.A.I.S. verbal 79, performance 95. Full scale 85 . Attainments.-reading age 9.6 years, spelling age $7 \cdot 7$ years.

Progress.-Settled well with simple psychotherapy. Refused reading help.

\section{Case 7}

A 28-year-old male nursing assistant was admitted to a neurological ward for investigation of headaches of three years' duration. These were accompanied by "turns" when he felt unable to move, and was weak and tremulous, and although he did not lose consciousness he was only dimly aware of his surroundings. Full neurological investigation showed no abnormality, and a psychiatric opinion was sought. His bedside locker was littered with medical and nursing textbooks, and on the ledge behind his bed several textbooks were ostentatiously displayed. He was working as a nursing assistant in a subnormality hospital, which he enjoyed. He had difficulty coping with any written work, however, owing to his reading difficulties, which he had kept secret. He had come under pressure to study for examinations, and it was after this that his "turns" became worse." He was cohabiting with a divorced woman who already had a child, but was reluctant to marry her, and this had led to rows. He was also sleeping in the home of an old lady on a paying basis to look after her. He was finding this an increasing chore as her physical condition deteriorated. 
It was felt that he was suffering from an anxiety state in relation to these difficulties, and he was treated as an outpatient.

Psychological Testing.-I.Q. W.A.I.S. verbal 68, performance 94. Full scale 78. Reading age 6 years (High subtest scatter. Those least dependent on verbal skills having the highest score.)

Progress.-He agreed to individual remedial help at the hospital at which he worked, and this was being continued.

\section{Treatment}

Treatment for dyslexia is difficult. Longstanding aversion to scholastic approaches is obvious, and motivation is low (Gann, 1945; Creak, 1930). Offers of help in a special reading clinic were too threatening as this reminded the patient of school and previous failures. Individual tuition would seem the only solution, but even this was rejected by most patients in this study. Three patients, however, did accept individual help. In case 2 the patient for whom only the offer of private tuition proved acceptable has made impressive progress. In this particular case there was strong motivation to overcome the dyslexia. Two patients (Cases 5 and 7) also accepted, and were oiven, individual remedial classes but stopped after a very short time. The others refused outright. For these psychiatric help was directed towards getting them to accept their disability and talk about it openly. They remained, however, highly vulnerable.

\section{Discussion}

In all these patients the dyslexia was not elicited by the general practitioners or physicians from whom all referrals came. In some cases it was not discovered at the initial psychiatric interview and became apparent subsequently, often only after further information had been obtained from relatives. It is thus highly likely that in many similar patients the dyslexia and associated difficulties remain undetected.

All the patients in this group had received conventional schooling, and there were no neurological or other physical abnormalities elicited. They showed certain personality characteristics. They were all extremely sensitive about their disabilities, and had over the years gone to great lengths to hide them from their families, friends, and workmates, avoiding situations where the disability would become apparent.

In the family, marital friction was commonly found in these patients, who, though highly dependent on their wives, resented this bitterly. In case 2 it was in fact the non-dyslexic wife who was referred for help. When the children in cases 1 , 4 , and 5 went to school and started to read this had apparently acted as the precipitant in their fathers' breakdowns.

Their existence in the community before referral had been a precarious one and specific stresses-for example, of job pro- motion demanding paperwork-had thus been effective in causing the patients disproportionate upset. A pattern of inferiority and mild paranoid reactions to others emergedsimilar to that described by McCready (1926) and Orton (1937) in children.

All the dyslexic patients reported on above were men. This is presumably because there are greater social pressures on men than on women. It must also be less humiliating for a wife to be unable to read and be dependent on her husband to do this for her, than vice versa. The various childhood series studied show an approximate 4 to 1 male: female ratio (Critchley, 1970).

The results of intelligence testing are likely to underestimate the patients' true ability on two counts. Firstly, poor results on verbal tests due to the dyslexia, and, secondly, poor performance in tests, this being the type of situation these patients had previously assiduously avoided. In some patients the actual reading and spelling ages obtained on testing were not in themselves markedly low (case 4), and some had previously attempted to overcome the difficulty themselves, but hesitancy and lack of fluency were pronounced, and reading still caused the patient major concern and embarrassment.

A survey by the National Association of Remedial Education (Daily Telegraph, 1971) concerning 400 illiterates, due to be published shortly, produced the following statements: A father: "I want to be able to keep pace with my 5-year-old daughter." A teenaged girl: "Learning to read will help me to get a boyfriend." A workman: "I can be a foreman as soon as I can read." Perhaps the most significant reply was "I want to be a normal person." The association stresses the very small proportion of adult illiterates that go to classes as a result of tremendous feelings of guilt and embarrassment.

We should like to thank Mr. M. Preston and Mr. J. Peel for the psychological testing, and for arranging the remedial programmes mentioned above.

\section{References}

Brown, R. I., and Bookbinder, G. E. (1966). Audio-visual Programmed Reading Material. Privately printed, Bristol.

Creak, M. (1930). Archives of Disease in Childhood, 2, 143.

Critchley, M. (1970). The Dyslexic Child. London, Heinemann.

Daily Telegraph, 1971, 25 August, p. 2.

Gann, E. (1945). Reading Difficulty and Personality Organisation. New York, Kings Crown Press.

Ingram, T. T. S. (1964). Practitioner, 192, 503.

Ingram, 1. T. S. (1964). Practitioner, 192, 003.

McCready, E. B. (1926). American fournal of Psychiatry, 6, 267. London, Chapman and Hall.

World Federation of Neurology (1968). Research Group on Developmental Dyslexia.

\section{Genital Yeast Infections}

\section{J. D. ORIEL， BETTY M. PARTRIDGE， MAIRE J. DENNY， J. C. COLEMAN}

British Medical fournal, 1972, 4, 761-764

\section{Summary}

Genital yeast infection was studied in 533 women seen in a department of venereology. Yeasts were recovered in

West London Hospital, Charing Cross Hospital Group, London S.W.6

J. D. ORIEL, M.D., Consultant Venereologist. (Present address: Department of Venereology, University College Hospital, London W.C.1)

Charing Cross Hospital Medical School, London W.C.2

BETTY M. PARTRIDGE, PH.D., Senior Lecturer in Mycology

MAIRE J. DENNY, A.I.M.L.T., Senior Technician in Mycology

J. C. COLLMAN, M.R.C.PATH., Senior Lecturer in Microbiology culture from 138 patients ( $26 \%$ of the total). Candida albicans accounted for $112(81 \%)$ of the isolates and Torulopsis glabrata for $22(16 \%)$; other yeasts were uncommon. There was no evidence that the presence of yeasts was related to age. $32 \%$ of the women who were taking an oral contraceptive harboured yeasts, compared with $18 \%$ of those who were not.

The symptoms and signs of the women with yeast infections were compared with those with vaginal trichomoniasis and those with no evidence of genital infection. It seems that a clinical diagnosis of vaginal mycosis cannot be made with accuracy and that positive identification of yeasts is necessary; for this, cultural methods are the most satisfactory. 